\title{
Análisis del espacio público frente a la pandemia en una urbanización informal argentina
}

Rocío Rodríguez Tarducci

ORCID: https://orcid.org/0000-0003-4627-3736

Correo electrónico: rociotarducci@hotmailgmail.com

Mariana Birche

ORCID: https://orcid.org/0000-0001-8621-4330

\section{Daniela Cortizo \\ ORCID: https://orcid.org/0000-0001-8953-3978}

Filiación institucional: Instituto de Investigaciones y Políticas del Ambiente Construido -CONICET- Universidad Nacional de La Plata, La Plata, Argentina.

\section{Resumen}

En urbanizaciones informales, los espacios públicos son de suma importancia para la recreación, socialización e incluso también para la economía de estas comunidades. Ante la amenaza del COVID-19, el funcionamiento, los requerimientos y características del espacio público se ponen bajo la lupa, y resulta interesante pensar en las nuevas realidades derivadas de la pandemia. El objetivo del trabajo es reconocer qué características presentan los espacios públicos en las urbanizaciones informales y cómo deberían adecuarse, contemplando los requerimientos de sus habitantes, en el contexto de la pandemia COVID-19 y de cara al futuro. Para tal fin, se analiza el caso del barrio Puente de Fierro, ubicado en la periferia sureste del Partido de La Plata, Buenos Aires, Argentina. El abordaje metodológico consiste en el análisis de distintas categorías de espacios públicos. Los resultados de la investigación permiten corroborar, a partir del caso de estudio, que estos espacios resultan indispensables para el quehacer diario de sus habitantes. Ante la escasez y el deterioro se plantean nuevos desafíos, atendiendo a la intervención y adecuación de espacios que contemplen los requerimientos de la población en situación de vulnerabilidad.

Palabras clave

Espacio público, pandemia, urbanizaciones informales, vulnerabilidad

\section{Analysis of public space in the face of the pandemic in an informal settlement in Argentina}

\begin{abstract}
In informal urbanizations, public spaces are of the utmost importance for recreation, socialization and even for the economy of these communities. Faced with the threat of COVID-19, the operation, requirements, and characteristics of public space are put under scrutiny, and it is interesting to think about the new realities derived from the pandemic. The objective of the work is to recognize what characteristics public spaces present in informal urbanizations, and how they should be adapted, considering the requirements of their inhabitants, in the context of the pandemic COVID-19 and heading to the future. To this end, the case of the Puente de Fierro neighborhood is analyzed. The neighborhood is located on the southeastern periphery of La Plata, Buenos Aires, Argentina. The methodological approach consists of the analysis of different categories of public spaces. The results of the research allow corroborating, based on the case study, that these spaces are essential for the daily activities of their inhabitants. Given the scarcity and deterioration, new challenges are posed for the future, considering the intervention and adaptation of spaces that take into account the requirements of the population in vulnerable situations.
\end{abstract}

\section{Keywords}

Informal urbanizations, pandemic, public space, vulnerability 


\section{Introducción}

En América Latina los problemas derivados del contraste entre la ciudad formal e informal son numerosos y afectan a los aglomerados urbanos más importantes, mayoritariamente en las áreas periféricas de las ciudades. En este marco, se entiende a la ciudad como un sistema complejo y a la complejidad como el producto de diferentes parámetros: la jerarquía, la no linealidad, la conectividad, la adaptación y la autoorganización. También se puede deducir que no existe una autoridad central. De esta forma, los comportamientos colectivos se forman a partir de reglas de interacción locales (no tienen en cuenta la totalidad) y, en función de ellos, se generan estados colectivos emergentes y estados de incertidumbre. Estos últimos, no invalidan el conocimiento, sino que lo perfilan, delimitan y nos obligan a conocerlo.

Solamente en América Latina existen más de 86 millones de hogares ubicados en urbanizaciones informales (villas, favelas comunas, etc.), sin acceso a los servicios urbanos básicos y localizados en zonas de fragilidad ambiental (Relevamiento Nacional de Barrios Populares, RENABAP, 2018). En el contexto de la pandemia que se ha desatado en el mundo entero, el COVID-19 afecta en gran medida a los habitantes de estas urbanizaciones, quienes pertenecen a sectores que se consideran entre los más vulnerables por no disponer de las mismas redes y sistemas de protección de las que gran parte de la población sí dispone.

Al interior de las urbanizaciones informales, los espacios públicos, que son comunes a todos los habitantes, representan lugares donde se despliegan estrategias de apropiación (material y simbólica), pero también generan interacciones (conflictivas, sinérgicas, contradictorias, cooperativas) entre actores respecto de la construcción y gestión de estos espacios. Con la situación de la pandemia esos espacios no resultan suficientes para cubrir las necesidades sanitarias ni recreativas de la población vulnerable. Por su parte, el Estado nacional argentino ha implementado protocolos de acción que se basan en la utilización de espacios públicos y, paralelamente, se alienta a los habitantes a usar los espacios verdes cercanos al domicilio, los cuales muchas veces no existen o se encuentran degradados (Myrick, 2020).

En este sentido, el entorno no facilita la implementación de medidas sanitarias adecuadas y, debido a ello, el hacinamiento y la ausencia de servicios básicos de salud de estas urbanizaciones (en parte, por su alta densidad poblacional), constituyen un potencial foco de contagio y propagación del virus. En Argentina, en particular en la provincia de Buenos Aires y su área metropolitana (AMBA), donde el virus ha golpeado con fuerza a estas urbanizaciones, esta realidad se hace evidente en el porcentaje de hogares que pertenece a estos barrios, llegando al 29\% del total de casos de la capital en mayo de 2020 (Jofré, 2020).

En este contexto, surgen algunos interrogantes acerca de qué características presentan los espacios públicos en las urbanizaciones informales, y cómo deberían adecuarse, contemplando los requerimientos de sus habitantes, en el contexto de la pandemia y de cara al futuro. En respuesta, se plantean las siguientes hipótesis:

1. Los espacios públicos en las urbanizaciones informales son insuficientes, se encuentran degradados, lo que hace que se conviertan, en el contexto de la pandemia y sumado a las condiciones del hábitat, en potenciales focos de contagio y propagación del virus.

2. La intervención en los espacios públicos de las urbanizaciones informales que contemplen los requerimientos de sus habitantes colaboraría a disminuir los riesgos de contagio y beneficiaría los procesos de socialización y esparcimiento.

En cuanto a la estructura del artículo, en primer lugar, se presentan los principales conceptos implicados en la problemática de la investigación, para indagar acerca de la relación entre el espacio público, la urbanización informal y la pandemia. En segundo lugar, se desarrolla la metodología a utilizar para el abordaje de la problemática, explicitando las técnicas cuantitativas, cualitativas y espaciales. Luego, se analiza el caso de estudio, el barrio Puente de Fierro en el Partido de La Plata, a partir de las distintas categorías de espacio público - espacio verde, 
espacio vial y espacio de socialización-. Por último, se presentan algunas estrategias que podrían ser de utilidad para la intervención de estos espacios, tomando en cuenta los requerimientos de la población y la factibilidad que otorga el territorio. Este último punto sienta las bases para trabajos futuros y abre el debate acerca de cómo deberían planificarse los espacios públicos para los más vulnerables.

\section{Marco teórico}

En Argentina, se considera urbanización informal a todo tipo de asentamiento cuyas formas de ocupación del suelo no se ajustan a las normas urbanísticamente establecidas, ni a los parámetros ambientales adecuados, y cuyas características físicas del entorno revisten cierto grado de precariedad. La informalidad puede presentarse tanto por la manera de acceder al suelo como por las características físicas del espacio (sobre áreas no aptas para el asentamiento, con lo que esto implica) (Clichevsky, 2003).

Las tipologías más extendidas en Argentina son las villas y los asentamientos informales. Si bien ambas tipologías son consideradas en su totalidad como urbanizaciones informales, existen diferencias entre ellas, principalmente en el modo de acceder al suelo; mientras que las villas surgen orgánicamente, los asentamientos informales requieren una logística y organización previa a la toma de la tierra. Esto, además, se ve reflejado, principalmente, en la morfología de cada una de ellas. Por su parte, las villas no siguen el trazado urbano de la "ciudad formal", presentan largos pasillos con entradas sin un trazado específico ni amanzanamiento y suelen densificarse, llegando en algunos casos hasta tres y cinco niveles de altura. Los asentamientos informales, por su parte, surgen de manera organizada, partiendo de la toma de la tierra (privada o fiscal), con apertura de calles y loteos imitando el trazado urbano existente, con el objetivo de lograr una rápida regularización (Rodríguez Tarducci, 2020).

Por otro lado, el espacio público, conceptualmente, se puede comprender a través de la visión de Mourier
(1998), según este autor, este concepto vehiculiza tres significados:

- Acción política: un vivir conjunto. Plantea el problema de la ciudadanía.

- Espacio cívico: expresión y libre cambio de opiniones.

- Civilidad (urbanidad): relación construida y distante de otros.

De este modo, es posible afirmar que cualquier otra postura que no incluya de manera explícita estas tres dimensiones, no estará resguardando los valores públicos y democráticos de la ciudad. El derecho a los espacios verdes, a la centralidad accesible y simbólica, a sentirse orgullosos del lugar en el que se vive y a ser reconocidos por los otros, a la visibilidad y a la identidad, además el disponer de equipamientos y espacios públicos cercanos, son también una condición de ciudadanía.

Delgado (1999) desarrolla un poco más la idea que emerge acerca del espacio público como lugar, y lo afirma como ámbito físico y simbólico, "esa arena para una vida social crónicamente insatisfecha es lo que la polis debe mantener en buenas condiciones, asegurando su plena accesibilidad" (p. 207). Esto es lo que hace que una calle o una plaza sean algo más que simplemente una calle o una plaza. Hace que un espacio teórico se convierta en un espacio sensible, parte esencial de la vida comunitaria en toda la ciudad.

Con relación a la ciudad física, el espacio público es un sistema que incluye tanto espacios exteriores abiertos como espacios interiores cerrados (Arroyo, 2011). Mientras que entre los primeros podemos encontrar plazas, calles y centralidades comerciales, en los segundos nos referimos al conjunto de edificios destinados a satisfacer necesidades colectivas de la población. Para los fines del presente trabajo, en relación con las urbanizaciones informales se considera apropiado trabajar con las categorías de la calle, el espacio público verde y los espacios de socialización (espacios interiores cerrados).

Respecto de la calle, esta se configura como el espacio de coalición entre las diferentes formas de movilidad y está 
destinada a unir los distintos puntos de la ciudad. Expresa notoriamente el modo de vida de sus habitantes, es decir, si existe una preferencia por los medios de transporte motorizados o no motorizados, públicos o privados, los cuales influyen directamente en la percepción pública y, por lo tanto, en su éxito o fracaso (debido a su alta visibilidad).

En relación con los espacios verdes, si bien se puede afirmar que existe un interés creciente en las áreas verdes metropolitanas, aún prevalece una visión tradicional y fragmentada del tema, al extremo de interpretar cada espacio verde como una unidad carente de vinculación con el medio donde se inserta (Garay y Fernández, 2013). Los espacios verdes se constituyen para la población en sus ámbitos principales de socialización, esparcimiento, representación y recreación en un entorno donde predomina la vegetación que además pertenecen al sistema de espacios públicos de la ciudad y deben estar comunicados a través de los espacios viales o calles. En este sentido, la ONU (2015) establece un mínimo de espacio público (vial y verde) del $35 \%$ en relación con la superficie urbana y recomienda hasta el 50\% para garantizar el sustento adecuado para la ciudad.

Por su parte, los espacios públicos "de socialización" (espacios interiores cerrados) pueden abarcar los equipamientos que desempeñan funciones básicas como salud, educación, seguridad, gobierno, justicia y cuya imagen, escala, modalidad de uso, gestión y propiedad se constituyen como equipamientos edilicios de la población (Arroyo, 2011).

En todos los casos se establece una relación entre una ciudad física (urbis) y una ciudad social (civitas). Sin embargo, mientras en la ciudad formal las distintas categorías de espacio público se constituyen en espacios concretos de socialización y esparcimiento, en la ciudad informal estos espacios presentan, además, otro nivel de complejidad. En las urbanizaciones informales, la calle se considera a menudo una extensión del hogar que, por lo general, es pequeño y limitado. Las puertas y las ventanas son los puntos de conexión y no es extraño encontrarlas abiertas, funcionando como elementos transicionales a través de los cuales el espacio abierto entra a la casa y la casa se extiende a la calle (Pérez Valecillos y Castellano Caldera, 2013). Como sostienen Takano y Tokeshi (2007),

esta impermeabilidad es un hecho que cotidianamente se ve alterado, y sus límites frecuentemente transgredidos. Estos intercambios entre lo público y lo privado se dan en las veredas en frente de cada casa, debajo de las escaleras exteriores, o de los techos y aleros que invaden la calle más allá de los límites del lote y se fusionan con ella: así la calle invade la casa, y la casa invade la calle (p. 55).

Así, los espacios públicos en los asentamientos informales tienen que ver más con la relación entre el interior de la casa y la calle, que con la dicotomía entre la privacidad del hogar y el carácter público del espacio abierto. En estos entornos urbanos de complejidad e incertidumbre creciente, el espacio público encuentra su lugar fundamentalmente a través de la forma calle tanto en las tipologías de villas como en la de asentamientos informales, dejando la posibilidad en estos últimos de integrar también una plaza o la típica canchita de fútbol (Riaño, 1990, citado en Hernández, 2011).

\section{Los espacios públicos y su rol en el marco del COVID-19}

En el contexto sanitario producto de la pandemia, las medidas de higiene y el distanciamiento social son aspectos esenciales como respuesta de salud pública para detener la propagación del virus. Sin embargo, la implementación de estas medidas representa un reto especialmente difícil para un gran porcentaje de la población que es considerada más vulnerable, es decir, aquellos que habitan en asentamientos informales, donde las condiciones de hacinamiento sumado a la falta de agua potable -entre otros déficits de servicios urbanos básicos- resultan más que propicias para la transmisión de todo tipo de enfermedades, especialmente el virus COVID-19 dado su alto grado de transmisibilidad. 
Las dificultades para acceder a servicios básicos como el agua potable, desagües cloacales o una vivienda en adecuadas condiciones en las villas y asentamientos generan una gran vulnerabilidad que se profundiza en el contexto de la pandemia. El hacinamiento, las condiciones ambientales y el déficit de servicios esenciales no permiten cumplir con las medidas recomendadas para evitar contagios. Asimismo, producto de la crisis económica, al interior de estos barrios, se ha cuatriplicado la concurrencia a comedores y copas de leche, según afirman vecinos en múltiples medios de comunicación. En este marco, como explica Fernández Marín (2016) "los sistemas urbanos están permanentemente sometidos a fenómenos potencialmente alteradores, a la transformación; se enfrentan en definitiva a la incertidumbre" (p. 21).

En este marco, el espacio público emerge como testigo tanto de la vida comunitaria como de las necesidades insatisfechas de estos sectores vulnerables y, en la actualidad, como espacio en crisis debido al surgimiento y expansión de la pandemia. Dado que el hombre es, ante todo, un ser social y esta característica condiciona sus actividades en todos los aspectos de su vida, el espacio público - como el lugar de la ciudad destinado a la socialización y a la vida pública- se convierte en foco de este trabajo por considerarse como prioritario, de modo que sea posible pensar en nuevas propuestas para su tratamiento, gestión y diseño.

\section{Metodología}

La metodología adoptada en este trabajo considera que las problemáticas urbanas se presentan en el marco de un sistema complejo como es la ciudad. Por ello, para llevar a cabo un análisis adecuado se utilizaron tanto técnicas cuantitativas, como cualitativas, especialmente aquellas que incluyen el análisis espacial.

El caso de estudio corresponde a una urbanización informal denominada Puente de Fierro, ubicada en la periferia sureste del Partido de La Plata, en la delegación de Altos de San Lorenzo. En este barrio viven aproximadamente 1.500 familias, según datos del Registro Nacional de
Barrios Populares del año 2018 (RENABAP).

Para la selección del caso, además de tener en cuenta las características propias por tratarse de uno de los asentamientos más grandes y con mayor cantidad de población del Partido de La Plata, también se contempló el acercamiento que existe en particular con el lugar, ya que allí una parte de los integrantes del equipo de trabajo desarrolla sus investigaciones desde el año 2016 (Bozzano, Canevari, Etchegoyen, Marín, Mateo, Bourgeois, Rodríguez Tarducci, Kain Aramburu, Fonseca Rodríguez, Vetere, Campuzano Castro y Babbini, I., 2020). Esto posibilitó la realización de entrevistas a cinco de los referentes representativos de las organizaciones sociales más importantes presentes en el barrio.

Para el abordaje del objeto de estudio, en primer lugar, se contextualizó la situación del espacio público del barrio en relación con tres escalas urbanas: el casco fundacional, la periferia y la delegación en donde está inserto. Los datos obtenidos con relación a la población y superficie de espacio público en las distintas escalas fueron comparados con los mínimos establecidos por la Organización de las Naciones Unidas (ONU, Hábitat III, 2015) y con las recomendaciones en el marco de la pandemia que señalan que los espacios públicos deben ser parte de la respuesta al virus, ya sea para limitar su propagación o para proporcionar formas para que las personas se relajen o lleven a cabo su sustento (ONU, Hábitat, 2020).

En segundo lugar, ya en el caso de estudio, se establecieron tres categorías para los distintos tipos de espacio público relevados al interior del barrio Puente de Fierro:

1. Espacio público, la calle: se lo considera como el espacio público por excelencia en los barrios vulnerables, donde los habitantes circulan diariamente y desarrollan actividades de todo tipo, entre ellas comerciales, recreativas y comunitarias y otras.

2. Espacio público verde: se refiere a plazas y espacios públicos abiertos (al aire libre) de dimensiones mayores a $200 \mathrm{~m}^{2}$, con una relación entre el ancho y el largo de uno y tres. Estos representan espacios que han disminuido su uso durante las etapas más 
Figura 1

Ubicación del Partido de La Plata

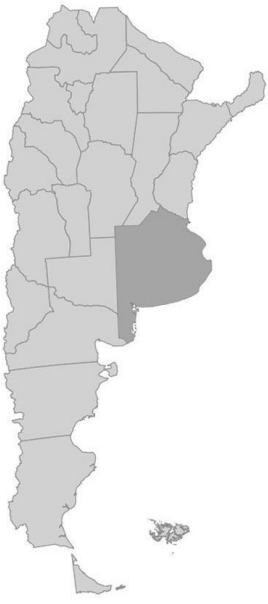

Argentina

$41,22 \mathrm{M}$ hab.

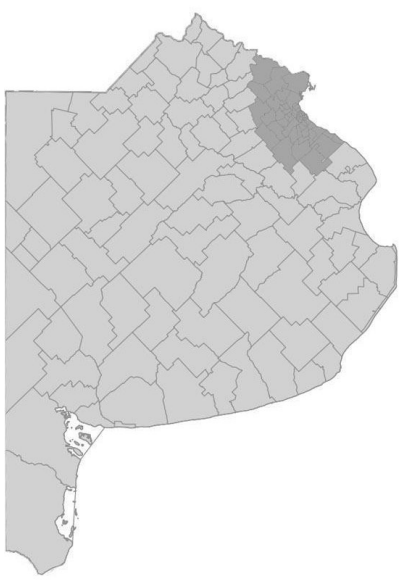

Provincia de Buenos Aires

$16,66 \mathrm{M}$ hab.

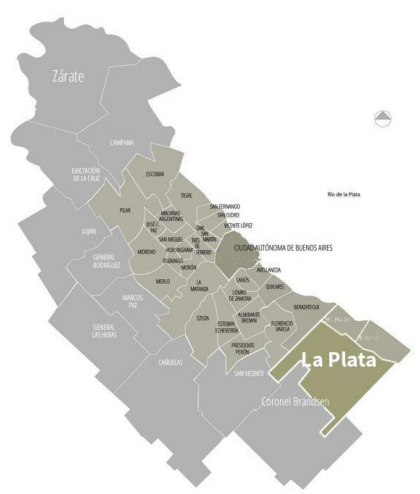

Gran Buenos Aires Partido de La Plata

13,58 M hab. 0,8 M hab. estrictas del confinamiento, pero que revisten un valor simbólico y de uso comunitario para la población, el cual se pudo constatar en las entrevistas con los principales referentes.

3. Espacio público de socialización: este es el caso de los espacios públicos o comunitarios que funcionan bajo cubierta como es el caso los comedores, algunos centros de atención primaria como las salitas de emergencias, los centros comunales, entre otros. Estos espacios suelen estar organizados por ONG o los propios vecinos, que lo adecuan para llevar a cabo las actividades de las que participan todos.

Este análisis se contrastó con aquellos datos de carácter cualitativo obtenidos a partir de entrevistas a informantes clave del barrio. Se realizaron cinco entrevistas a referentes (actores representativos pertenecientes a organizaciones sociales que trabajan dentro del barrio y lo conocen exhaustivamente), a quienes se les consultó acerca del uso del espacio público y del valor simbólico del mismo, tanto en momentos previos a la pandemia, como durante el confinamiento estricto. Los datos obtenidos se integraron y espacializaron en cartografías georreferenciadas realizadas en un Sistema de Información Geográfica (SIG).

Luego del análisis del espacio público al interior del caso de estudio, se desarrolló una instancia de investigación de carácter propositivo. En este sentido, se presentan algunas propuestas, a partir de la identificación de tierras vacantes aledañas al barrio, que podrían aplicarse como herramientas para la creación de nuevos espacios comunitarios, que cumplan la función de convertirse en lugares estratégicos. Las tierras vacantes se caracterizan como áreas que se encuentran no utilizadas (sin uso), que pueden estar vacías (sin edificación) o con alguna edificación abandonada, y que pueden ser de propiedad privada o fiscal (Clichevsky, 2007; Cortizo, 2020). En líneas generales, resulta posible identificar algunas de ellas próximas a urbanizaciones informales que podrían utilizarse para tales fines. Se plantean lugares inclusivos, solidarios y sanitarios claves para disminuir el impacto negativo del COVID-19 sobre la comunidad y a su vez remediar la falta de espacios verdes para la socialización, problemática que arrastran estos barrios desde hace años y que se ha hecho aún más urgente en el contexto de la pandemia.

\section{Resultados}

Como se mencionó, el barrio Puente de Fierro se encuentra localizado en la ciudad de La Plata, capital de la provincia de Buenos Aires, ubicada a 56 kilómetros de la capital del país, la Ciudad Autónoma de Buenos Aires. La ciudad tiene una población aproximada de 900.000 habitantes, según estimaciones del Instituto Nacional de Estadística y Censos de la República Argentina, INDEC, para el año 2020, lo que la convierte en la cuarta más poblada de Argentina (Figura 1).

La ciudad posee un casco fundacional diseñado ex novo en 1882 que, con el paso de los años, ha adoptado un modelo de crecimiento difuso, creando grandes áreas 


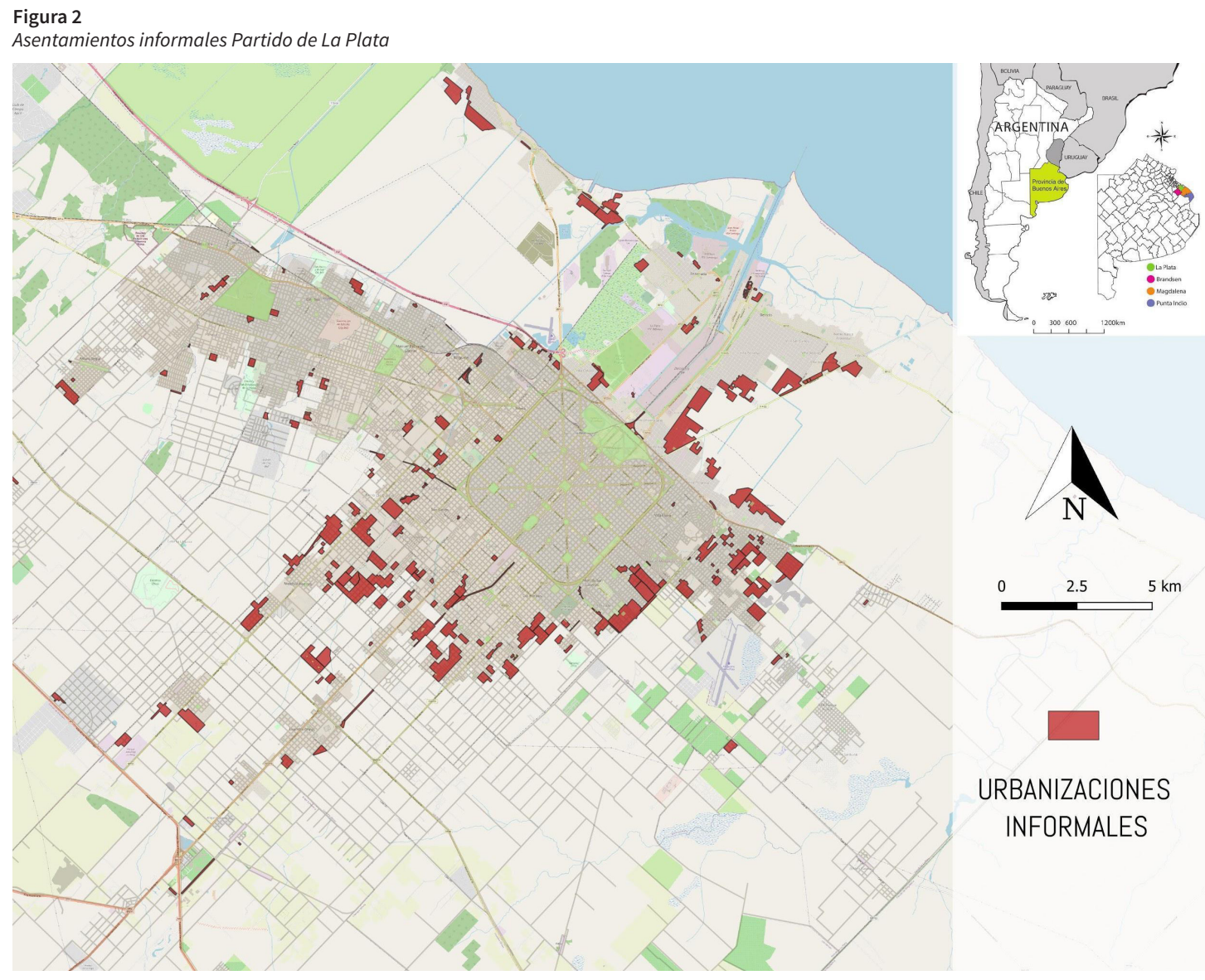

urbanas periféricas que desbordan de este. En el área que corresponde a la periferia del Partido de La Plata, se reconocen 153 urbanizaciones o barrios catalogados como informales, según RENABAP, el cual se llevó a cabo en el año 2018 (Figura 2). Esto equivale a aproximadamente 40.126 familias que viven en condiciones de precariedad - cerca del $20 \%$ de la población del Partido de La Plata vive en urbanizaciones informales-y que, al igual que resto de la población, requieren de espacios para la recreación y circulación apropiados. Estos barrios se encuentran localizados en áreas de fragilidad ambiental, en condiciones de vulnerabilidad sin acceso adecuado a los servicios urbanos básicos, tales como el agua potable, gas, red de cloacas y energía eléctrica. También presentan condiciones de hacinamiento y precariedad al interior de las viviendas. La aplicación del Aislamiento Social Preventivo y Obligatorio (ASPO) en Argentina, entre marzo a diciembre del año 2020, ha sido difícil para estos barrios, principalmente debido al hacinamiento y a las condiciones precarias del hábitat. Esta es una clara manifestación del modo en que la pandemia puso de manifiesto la inequidad social y estructural. Como se mencionó, una de las características más comunes observadas dentro de las urbanizaciones informales corresponde a la ausencia o la escasez de espacio público de calidad que facilite la vida en comunidad. Esta situación se explica a partir del origen de este tipo de urbanización, ligado a procesos urbanos por fuera de las normas urbanísticas.

El espacio público en contextos de informalidad, al igual que la vivienda, es en gran medida producto del accionar de los mismos habitantes, quienes transforman el territorio para adecuarlo a sus necesidades. Estos espacios por lo general son utilizados por los residentes casi exclusivamente, y son entendidos como espacios comunitarios. Es por lo que las prácticas sociales y culturales resultan relevantes, ya que definen las interacciones entre los habitantes y el espacio público, mientras que, del mismo modo, este se transforma en virtud de esas interacciones. Si bien el rol del espacio público en este tipo de urbanización es de primera necesidad y se vincula con la vida comunitaria, la recreación y las prácticas culturales de la población, en 
Tabla 1

Comparación entre la cantidad de espacio público disponible en Puente de Fierro y los sectores de ciudad formal de su entorno inmediato

\begin{tabular}{|c|c|c|c|c|c|c|c|}
\hline Zonas de análisis & $\begin{array}{l}\text { Población } \\
\text { estimada } \\
2019 \\
\text { habitantes }\end{array}$ & $\begin{array}{l}\text { Superficie } \\
\text { urbana } \mathrm{Ha}\end{array}$ & $\begin{array}{l}\text { Densidad } \\
\text { promedio } \\
\mathrm{Hab} / \mathrm{Ha}\end{array}$ & $\begin{array}{l}\text { Espacio vial } \\
\text { y peatonal } \\
\mathrm{Ha}\end{array}$ & $\begin{array}{l}\text { Espacios } \\
\text { verdes } \\
\mathrm{Ha}\end{array}$ & $\begin{array}{l}\text { Espacio } \\
\text { público } \\
\text { total } \\
\mathrm{Ha}\end{array}$ & $\begin{array}{l}\text { Porcentaje } \\
\text { EPT }\end{array}$ \\
\hline $\begin{array}{l}\text { Casco fundacional } \\
\text { (centro) }\end{array}$ & 225.761 & $2.798,5$ & 80,7 & 825,2 & 373,22 & $1.198,4$ & 42,8 \\
\hline Periferia Desborde & 338.413 & $7.849,2$ & 43,1 & $1.464,4$ & 91,3 & $1.555,7$ & 19,8 \\
\hline Altos de San Lorenzo & 41.435 & 875,6 & 47,3 & 171,6 & 7,38 & 179,0 & 20,4 \\
\hline B. Pte. Fierro & 5.300 & 83,68 & 63,3 & 22,09 & 0,67 & 22,76 & 27,2 \\
\hline
\end{tabular}

la actualidad, la disponibilidad de este tipo de espacio no parece ser el adecuado ni suficiente para sus demandas.

\section{El espacio público en el barrio Puente de Fierro}

El barrio Puente de Fierro representa una de las 153 urbanizaciones informales del Partido de La Plata, correspondiente a la localidad de Altos de San Lorenzo. Esta urbanización constituye una de las de mayor cantidad de población, con alrededor de 5.300 habitantes según datos del RENABAP. Asimismo, es considerada como una de las urbanizaciones informales con mayor presencia de organizaciones sociales del Partido, en donde el trabajo social para la creación y mejoramiento de espacios comunitarios está muy presente entre sus habitantes.

Al realizar la contabilización de los distintos tipos de espacio público en Puente de Fierro, se obtuvieron los resultados presentados en la Tabla 1.

Estos datos, permiten corroborar que el barrio Puente de Fierro cuenta con mayor porcentaje de espacio público que el total de la localidad de Altos de San Lorenzo, debido a que presenta mayor densidad de calles (Figura 3). Sin embargo, y debido a su falta de espacios verdes, no alcanza el porcentaje recomendado por la ONU que es del 35\% (ONU Hábitat III, 2015).

A partir del trabajo de campo y el análisis cualitativo obtenido de las entrevistas a informantes clave, en el barrio pueden identificarse las tres categorías de espacio público adoptadas, con un alto valor de carácter material y simbólico colectivo en cuanto a su uso y apropiación.

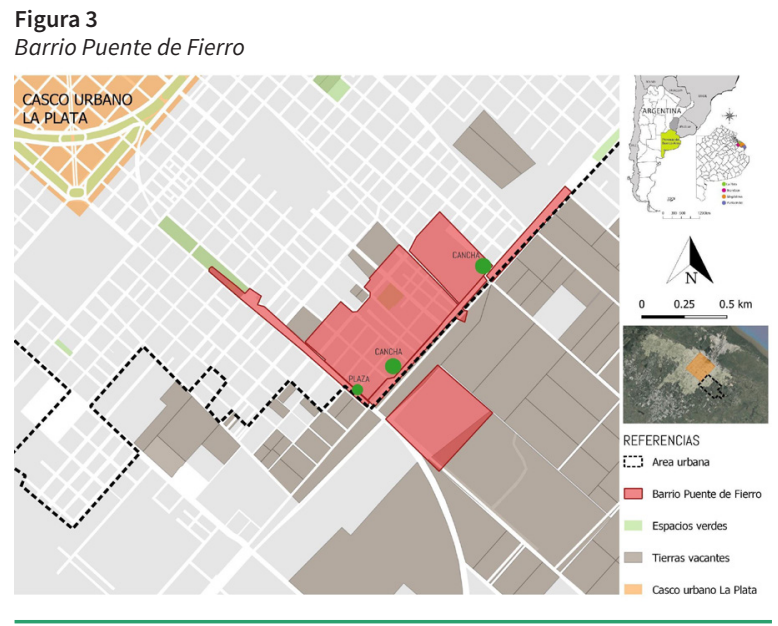

\section{Espacio público, la calle}

La calle representa uno de los espacios públicos de mayor relevancia dentro del barrio, simboliza una extensión del hogar y un lugar de encuentro para los vecinos. Resulta muy común en Puente de Fierro observar niños jugando en las calles, son lugares muy transitados por los vecinos que aprovechan los encuentros ocasionales para conversar.

En la calle, además de la circulación peatonal diaria, se realizan distintas actividades comerciales y recreativas, como se puede observar en la Figura 4, que durante la etapa más estricta del confinamiento se vieron restringidas, afectando en muchos casos la economía de vendedores ambulantes.

Se les consultó a los referentes acerca de los requerimientos vinculados con el espacio "calle". En este sentido el 


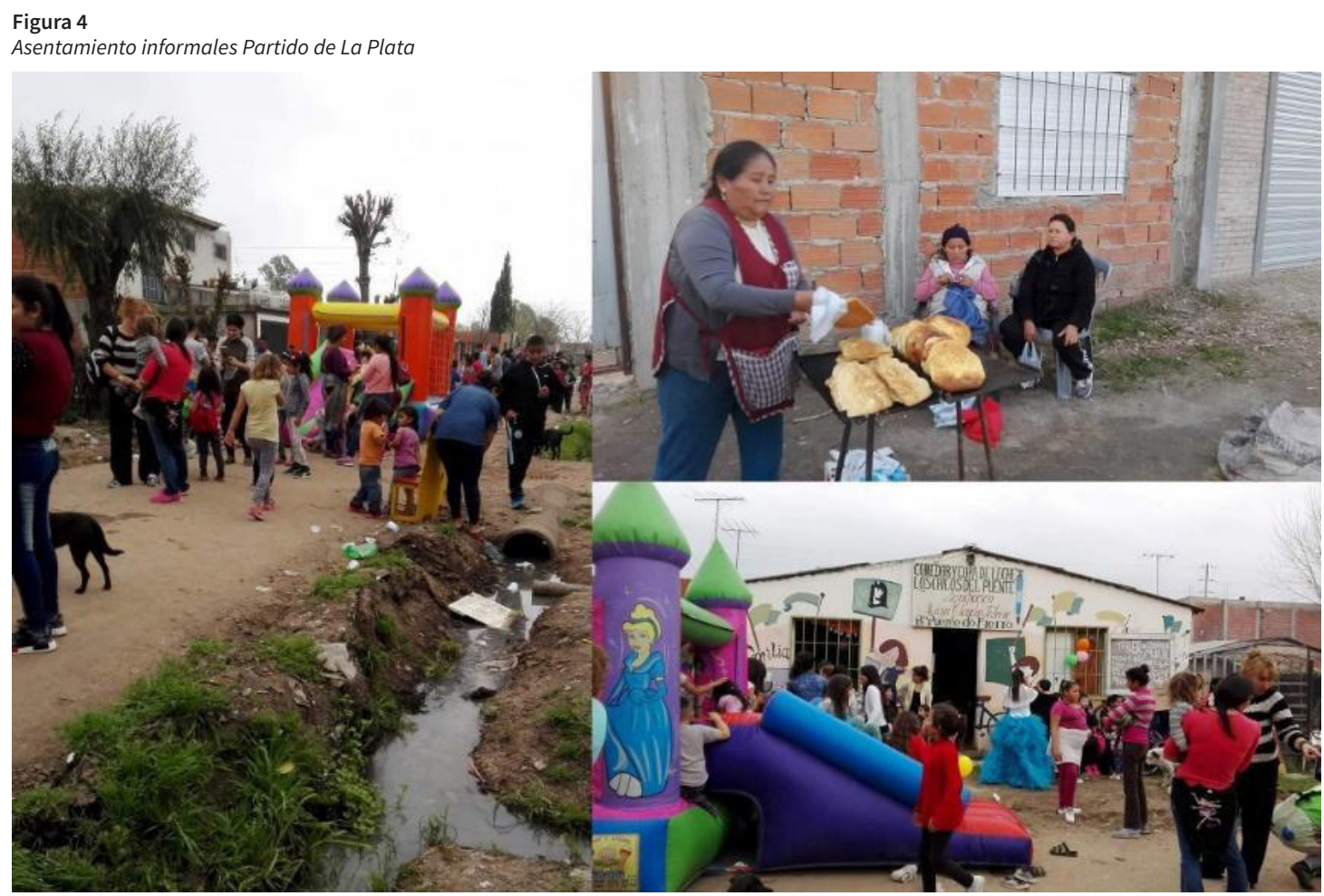

referente 4 menciona "uno de los problemas que tenemos acá en el barrio son las veredas todas rotas, hace años nadie las arregla". Por su parte el referente 2 agrega: "Los zanjones traen muchos problemas para todos los vecinos, se acumula la basura en lugares donde los chicos juegan”.

\section{Espacio público verde}

Por lo general, en las urbanizaciones informales, los habitantes suelen recurrir al uso de tierras vacantes como lugares para la recreación y, en este sentido, en el esparcimiento dentro de los barrios resulta muy común la práctica de la autogestión de plazas.

En el caso particular de Puente de Fierro, es posible identificar dos plazas que corresponden a la categoría de espacio público verde. Por un lado, se encuentra la denominada canchita que se utiliza principalmente con fines deportivos y, por el otro, la placita del barrio, que, a diferencia de la canchita, es una plaza seca con juegos para niños. Ambos espacios cumplen con funciones similares, principalmente de recreación de los habitantes, como puede observarse en la Figura 5. Asimismo, estos espacios se utilizan para reuniones donde participan muchas de las organizaciones sociales y vecinos, en donde se debaten temas referidos al mejoramiento del barrio, en especial, en días donde el clima no permite la reunión en espacios cerrados.

Respecto de la pandemia, y teniendo en cuenta el distanciamiento social, se han utilizado estos espacios para continuar con las reuniones, por ser al aire libre y permitir el cumplimiento de los protocolos sanitarios.

Cabe mencionar, como contrapunto a los aspectos positivos que representan estos lugares, que las dos plazas no son suficientes para cubrir las necesidades de las casi 5 mil familias que habitan en el barrio. Esta situación se complejiza aún más cuando, en el contexto de la pandemia, se habilitan las reuniones al aire libre en espacios públicos como lugares seguros para la socialización. Al respecto el referente 2 menciona:

Acá en el barrio necesitamos más plazas, lugares para ir a tomar mate y que los chicos puedan jugar un rato al aire libre. A veces estás en la placita y ves que se llena de gente y a mí eso un poco me da miedo con el COVID.

En el contexto de la pandemia por COVID-19, y en relación con el análisis del espacio denominado verde público, se realizó una serie de preguntas a los principales referentes 
Figura 5

La canchita de Puente de Fierro y la placita del Puente

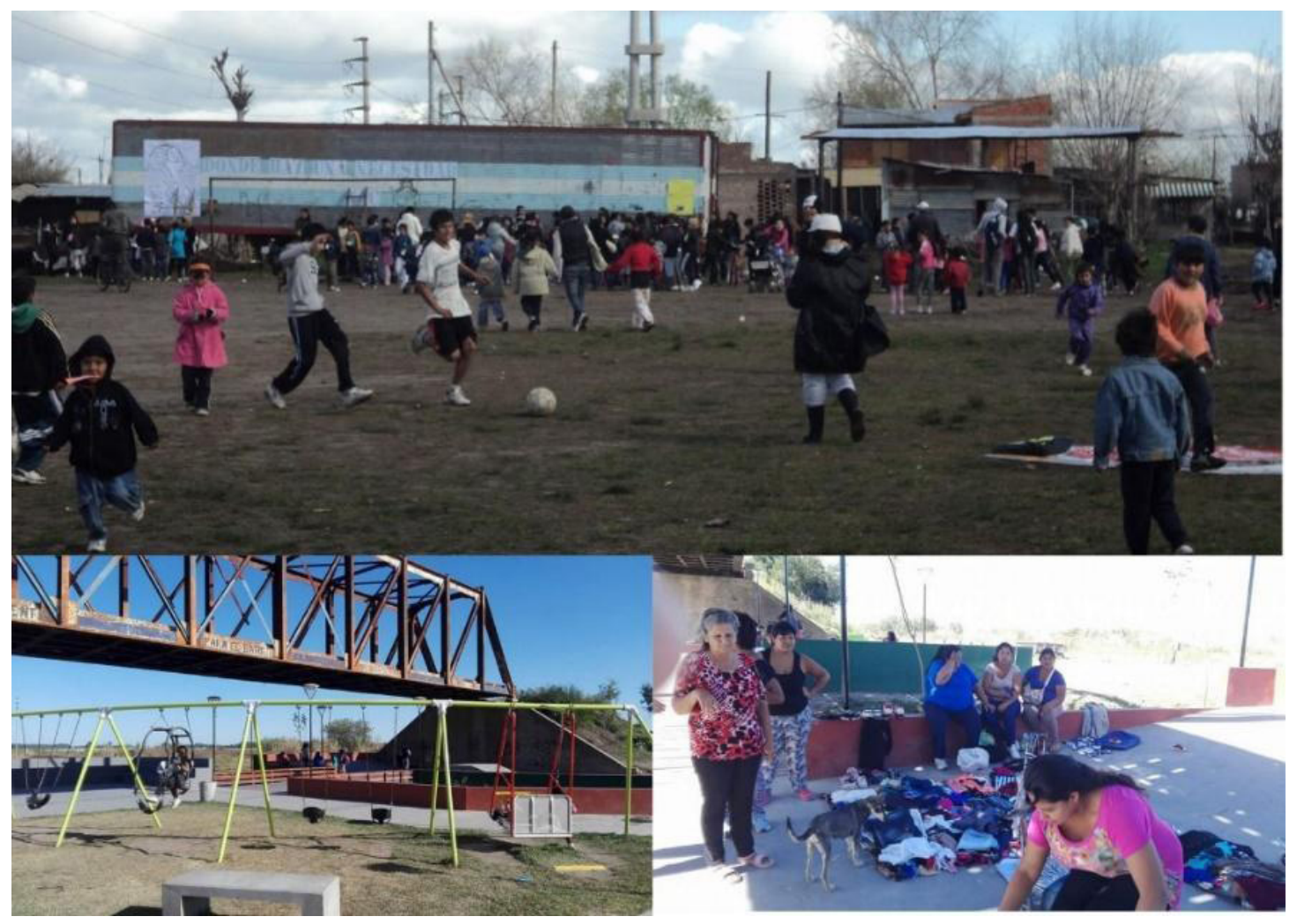

del barrio Puente de Fierro sobre el uso de este. Algunas de ellas apuntan a reconocer si en la actualidad se continúan utilizando estos espacios con normalidad, o si por el contrario algo ha cambiado respecto del modo en que son concebidos por los habitantes del barrio, por ejemplo, si se ha incrementado su uso diario o semanal. Con respecto al primer interrogante, si bien los espacios comunes que muchos denominan la canchita y la placita constituyen lugares muy utilizados por los vecinos del barrio, los referentes coinciden en que el uso de estos ha disminuido en el inicio de la pandemia, sobre todo, durante las fases más estrictas del confinamiento. Sin embargo, con la apertura progresiva de actividades, estos espacios fueron retomando su uso habitual. En este sentido, el referente 3 agrega: "Los chicos volvieron a jugar al fútbol en la canchita, eso les hace bien y se divierten". Otra de las preguntas indaga acerca del estado de estos espacios, respecto de la limpieza y mantenimiento. En este sentido el referente 4 explica:

La gente no cuida, muchos de los juegos están rotos y algunos vecinos nos ponemos de acuerdo para arreglarlos. También está el tema de la basura, cada vez hay más basura y somos nosotros los que tenemos que ir a limpiar.

\section{Espacio público de socialización}

$\mathrm{Al}$ interior del barrio, estos espacios se diferencian de los anteriores, ya que son interiores cerrados, como por ejemplo los comedores comunitarios. Estos son lugares de socialización de los vecinos, o en espacios como el container que funciona como sala de reuniones ubicado en la placita (Figura 6).

En el caso de los comedores comunitarios y de las copas de leche, la situación se presenta algo diferente, dado que son espacios que aumentaron su demanda en el contexto de la pandemia, puesto que la cantidad de familias que llega a ellos en busca de viandas alimentarias se ha incrementado exponencialmente durante los últimos meses del año 2020. Los referentes afirman que la mercadería no alcanza a cubrir las necesidades de la población y, si bien los vecinos no comen en el lugar como lo hacían habitualmente, sino que retiran las viandas, en las calles se generan largas filas 
Figura 6

Espacios públicos de socialización en Puente de Fierro

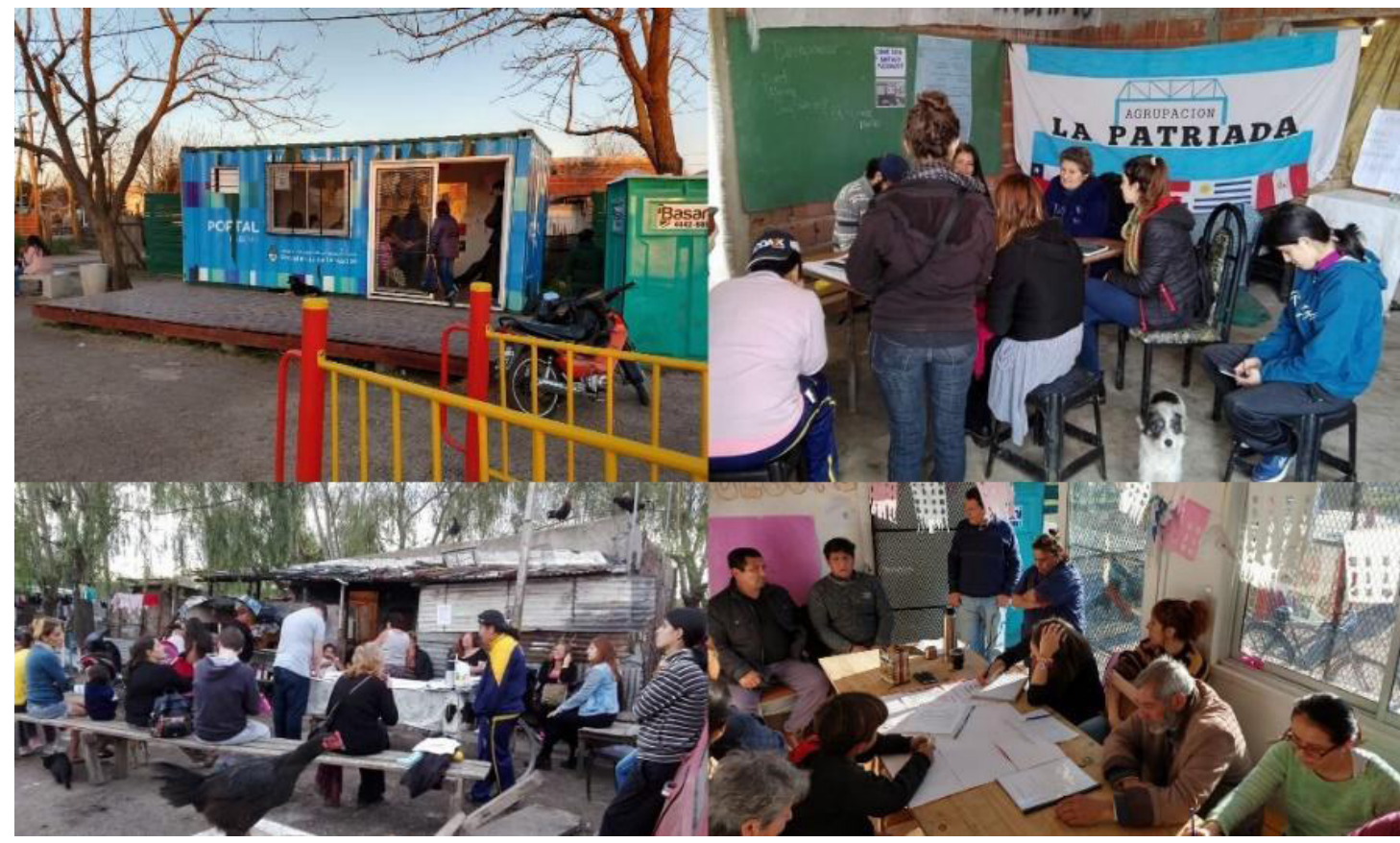

de espera y del mismo modo aumenta la circulación de personas dentro el barrio.

Los referentes indican que esta situación no es lo suficientemente segura para satisfacer las necesidades de la población y, al mismo tiempo, prevenir el contagio de COVID-19 al interior del barrio, manifestando que:

No tenemos lugares para guardar y repartirle a la gente los insumos para que hagan la limpieza, a veces cuando traen se juntan en los comedores, pero sería bueno tener un lugar a donde llegue toda la mercadería junta (Referente 2).

Esto se suma a las situaciones de emergencia que puedan ocurrir, no existen lugares dentro del barrio con información suficiente acerca de qué hacer ni a dónde recurrir en caso de urgencias, no siempre relacionadas con la situación sanitaria. Por lo antes dicho, sería importante pensar en espacios comunes dentro del barrio que contemplen este tipo de situaciones, más aún en el contexto actual de la pandemia.

\section{Discusión}

La planificación de ciudades tal como la conocemos está cambiando. Por ello, uno de los interrogantes más recientes busca avanzar sobre ¿cómo incluir en la ciudad a los sectores más vulnerables de la sociedad? Siguiendo esta línea, a partir del análisis del caso y los resultados presentados, nos preguntamos: ¿debemos modificar la manera cómo planificamos el espacio público para minimizar los riesgos y aumentar las prestaciones de estos de cara al futuro? Esto representaría un cambio en el paradigma de ciudades inclusivas, basado en la incorporación de un espacio público solidario que fomente la interacción social segura entre los vecinos y también con un Estado presente al alcance de todos. En esta línea, Gehl (2006) plantea que las ciudades vivas son aquellas en las que las personas pueden interactuar con otras personas, y son siempre estimulantes porque son ricas en experiencias, en contraste con las ciudades sin vida. Las personas son atraídas por otras personas y prefieren estar donde están otros. En este punto, surgen entonces dos premisas para debatir y reflexionar desde la planificación urbana actual y el paradigma emergente.

Planificar la incertidumbre para la inclusión: el derecho a la ciudad, el derecho al espacio público de calidad

Borja (2003) asocia el concepto de espacio público al de instrumento, entendiéndolo como una herramienta de transformación de la ciudad. El autor plantea algunas 
estrategias para regenerar el espacio público de la ciudad y también propone una serie de derechos ciudadanosurbanos como contribución a la renovación de la cultura política en el ámbito de la ciudad y del gobierno local. Es decir, refiere a derechos directamente vinculados con la política de y en la ciudad, necesarios para legitimar las demandas locales y la síntesis entre valores universalistas y prácticas políticas territoriales. Entre los derechos que plantea se encuentran: derecho al lugar; derecho al espacio público y la monumentalidad; derecho a la belleza; derecho a la identidad colectiva dentro de la ciudad; derecho a la movilidad y a la accesibilidad; derecho a la centralidad; derecho a la conversión de la ciudad marginal o ilegal en ciudad de ciudadanía; derecho a la ciudad metropolitana o plurimunicipal; derecho al acceso y al uso de las tecnologías de información y comunicación; derecho a la ciudad como refugio; entre otros. Al respecto, no se puede dejar de mencionar el derecho a la ciudad, como lo describe Henri Lefebvre en 1967 como el derecho de los habitantes urbanos a construir, decidir y crear la ciudad como una alternativa a la despolitización que el urbanismo moderno produjo en la sociedad y promovido por los Estados modernos. Particularmente para el caso de La Plata, es importante destacar la importante relación entre áreas planificadas y no planificadas en lo que respecta al espacio público. Se constató a partir del porcentaje de espacio público, la diferencia existente entre las urbanizaciones previamente planificadas de las que fueron creciendo por la acción privada, sin normativas responsables (Birche, 2020).

\section{Herramientas para alcanzar el punto 1: nuevos espacios públicos inclusivos}

Es cierto que en las tipologías que corresponden a villas, planificar el espacio común resulta complejo debido al tejido y la gran densidad, pero es posible la planificación a partir de repensar la calle propiamente dicha, los pasillos, la canchita o lugares comunes utilizados diariamente por los vecinos, recrear espacio de socialización seguros y comunitarios.

En el caso de las urbanizaciones informales en la periferia del Partido de La Plata, se pudo observar a través de la información obtenida en las entrevistas, que los habitantes suelen preferir los vecindarios que se han desarrollado gracias a las contribuciones y accionar colectivo.

En este tipo de barrios existe un mayor porcentaje de espacios públicos del tipo "calle", que si bien en el caso de Puente de Fierro son acompañados por escasos espacios públicos nodales, como pueden ser las dos canchas de fútbol, estos llegan a representar un $27 \%$ de la superficie del asentamiento, un porcentaje muy superior al de la periferia de su entorno inmediato que se corresponde con los sectores de urbanización formal de la ciudad (los cuales apenas alcanzan el 20\%). Este porcentaje de espacio público, si bien no llega a lo recomendado por la ONU debido a la falta de espacios verdes, vemos que representa un alto porcentaje respecto de los espacios públicos viales y peatonales. Por este motivo resulta necesario revalorizar estos espacios que en la actualidad plasman los intensos vínculos que estas comunidades mantienen entre vecinos, ya que la calle es el lugar de encuentro por excelencia. Es decir, más que cualquier otra cosa, la ciudad es su espacio público peatonal. La cantidad y la calidad del espacio público peatonal determinan la calidad urbanística de una ciudad (Gehl, 2006).

Respecto de la falta de espacios verdes, resulta una paradoja que existan tantos espacios vacantes posibles de renacionalizarse: en La Plata, las tierras vacantes de una manzana o más grandes representan el 18,3\% del total de la superficie del área urbanizable del Partido (Cortizo, 2020). Estas áreas podrían utilizarse en pos de generar nuevos espacios para la inclusión, fomentar otros para la recreación y también para el desarrollo de las economías solidarias y comunitarias. En este contexto, tratando de suplir esta escasez de espacios verdes hemos visto que los sectores vulnerables, al igual que la periferia formal, buscan formas de autogenerarlos, apropiándose de tierras vacantes (tanto desocupadas como en desuso, tal como las ex estaciones de ferrocarril).

En las cercanías al barrio Puente de Fierro se localizan tierras vacantes que podrían utilizarse (Figura 4), a partir de la planificación y adaptación de estos espacios desde el diseño formal por parte del gobierno local. La 
existencia de tierras vacantes dispersas en la trama urbana constituye una problemática actual en las ciudades en general, lo que implica la posibilidad de pensarlas como lugares con potencialidad de uso temporal (mientras no se utilizan por sus propietarios para otros fines), teniendo como principio el "urbanismo temporal", que tiene como fin movilizar recursos limitados (en este caso, la tierra) por plazos determinados con el fin de lograr una recuperación satisfactoria de estos espacios, para satisfacer las necesidades y demandas actuales de la comunidad (Parejo Alfonso, 2016). En este marco, la dinamización temporal de estos espacios vacantes "parte de una concepción participativa, de la necesidad de empoderar a los vecinos para que actúen como impulsores de proyectos en su espacio de convivencia o, cuanto menos, para que se sientan creadores del lugar, reapropiándose del mismo" (Gifreu Font, 2016, p. 136).

Teniendo en cuenta que gran cantidad de estas tierras sin uso son de dominio privado, para poder utilizarlas es necesario activar desde el municipio diversos instrumentos de gestión, entre los que se puede mencionar la concesión de uso. Se trata de un instrumento jurídico por medio del cual el municipio podría utilizar la tierra que pertenece al privado por un plazo determinado. Se formaliza a través de un contrato administrativo mediante el cual el que ejerce el dominio de la tierra vacante (el Estado en cualquiera de sus niveles, o un privado) acuerda el uso de esta durante un período determinado, recibiendo un canon u otra contraprestación que se fije previamente (Cortizo, 2020).

Se puede mencionar como antecedente en La Plata el Programa "Chau baldío" (2008), con el objetivo de "afectar inmuebles ubicados en el radio del Partido para destinarlos al emplazamiento de espacios verdes, parquización, plazas o centros comunitarios”. Para tal fin, el mecanismo consistía en suscribir un convenio con el titular de dominio, y el municipio era el encargado de la construcción de la plaza y su mantenimiento, hasta el eventual vencimiento del convenio. La cesión nunca era inferior a tres años, pudiendo renovarse. Además, la ordenanza contemplaba que "entidades de bien público, organizaciones comunitarias y vecinos podrán elaborar propuestas de intervención y/o mantenimiento de los predios afectados mediante los convenios suscriptos" (Frediani, 2016).

En el caso de las tierras vacantes de dominio público, pueden identificarse dos (las localizadas sobre avenida 90) que, al ser de propiedad del propio Estado, podrían utilizarse como espacio público temporal de una forma más rápida, en el marco de la Ley Nacional № 24.146, la cual dispone la transferencia a título gratuito a favor de provincias, municipios y comunas de bienes inmuebles innecesarios para el cumplimiento de sus fines o gestión. Sobre estas tierras vacantes sería posible instalar módulos, tanto móviles como flexibles, que pueden tener distintos usos, como, por ejemplo, el proveer información y servicios para asistir a los habitantes de estos barrios más vulnerables en el contexto de la pandemia. En este sentido, repensar el espacio público en función de la problemática actual del COVID-19 plantea otorgarles función y uso a esos espacios vacantes de manera temporal, logrando así hacer frente y responder algunas cuestiones sobre la problemática actual. En definitiva, de eso se trata planificar la incertidumbre.

\section{Conclusiones}

A partir del análisis presentado, se pone de manifiesto que el espacio público debe ser considerado no solamente como un indicador de calidad urbana, sino también, como un instrumento de la política urbanística útil para hacer ciudad sobre la ciudad y para lograr el encuentro entre todos sus habitantes, iguales y/ diferentes. También se pone de manifiesto que los encargados de la planificación del espacio urbano deben afrontar los nuevos desafíos, pudiendo ser permeables a las nuevas necesidades y requerimientos de la población. Si bien se observa que en los sectores vulnerables existe cierta falta de espacios verdes de calidad, en relación con la gran cantidad de población que los habita, la intensa vida de sus calles angostas, junto con la actividad constante dentro de ellos, han creado un entorno urbano que prioriza principalmente la circulación peatonal y en bicicleta, aportando experiencias urbanas de barrio y escala humana a la comunidad. 
Particularmente para el caso de estudio, se ha constatado que los espacios públicos resultan escasos tanto en relación con la superficie urbana ocupada, como también respecto del intenso uso que hacen los habitantes del barrio. Esta situación, sumada a las necesidades en el contexto de la pandemia, han resultado ser espacios públicos insuficientes y degradados, los cuales se constituyen como potenciales focos de contagio y propagación del virus. Asimismo, los espacios públicos existentes podrían adecuarse, contemplando los requerimientos de sus habitantes, y a su vez incrementarse a partir de la intervención de tierras vacantes aledañas. Esto colaboraría a disminuir los riesgos de contagio y beneficiaría los procesos de socialización y esparcimiento, en el contexto de la pandemia y de cara al futuro.

Con respecto a la primera categoría de espacio público, la calle, a partir de los dichos de los referentes, se llegó a la conclusión de la necesidad de acondicionar las veredas y realizar el saneamiento de las zanjas que, como señalan, representan un peligro para la salud de los habitantes. Para la segunda categoría, espacios verdes, se propone incrementar la superficie de estos (utilizando las tierras vacantes aledañas) asegurando el acceso de todos los habitantes; asimismo, el acondicionamiento, mantenimiento y limpieza periódica de los juegos y la incorporación de campañas de concientización acerca del cuidado del espacio público, principalmente respecto de la basura. En cuanto a la tercera categoría, se plantea la necesidad de adecuar los espacios a los nuevos requerimientos sanitarios, contemplando lugares para el acopio y reparto de insumos sanitarios y alimenticios para los habitantes.

Se desprende que el análisis y la planificación adecuada del espacio público resulta de primera necesidad para las comunidades más vulnerables, quienes dependen de estos lugares para continuar el funcionamiento de sus economías comunitarias, generar espacios de socialización y satisfacer sus necesidades básicas como comunidad. Como señala Han (2020), “el coronavirus está mostrando que la vulnerabilidad o mortalidad humanas no son democráticas, sino que dependen del estatus social” (s.p.). En este marco, la sociedad se constituye en la expresión de realidades físicas y sociales que expresan a su vez la exclusión y el desamparo de muchos, frente a los privilegios y al pleno disfrute de las libertades urbanas de otros (Borja y Muxí, 2001). Es por esto que el recurso común más importante para las ciudades es el elemento capaz de actuar como democratizador frente a todas estas circunstancias: el espacio público. Ante la incertidumbre que genera la situación de la pandemia y el hecho de no saber cómo se será la "nueva normalidad", se presenta una oportunidad, tal y como la representa el poder repensar los espacios de habitar, con una mirada inclusiva, con justicia social equitativa, y que por demás garantice el derecho a la ciudad para todos sus habitantes.

\section{Referencias bibliográficas}

Arroyo, J. (2011). Espacio público. Entre afirmaciones y desplazamientos. Universidad Nacional del Litoral.

Birche, M. (2020). El sistema de espacios públicos como factor estructurador de la calidad del paisaje y el ambiente urbano [Tesis de doctorado no publicada]. Facultad de Arquitectura y Urbanismo. Universidad Nacional de La Plata.

Borja, J. (2003). La ciudad conquistada. Alianza Editorial.

Borja, J. y Muxí, Z. (2001). Espacio público: ciudad y ciudadanía. Editorial Electa.

Bozzano, H., Canevari, T., Etchegoyen, G., Marín, G., Mateo, G., Bourgeois, M., Rodríguez Tarducci, R., Kain Aramburu, I., Fonseca Rodríguez, J., Vetere, P., Campuzano Castro, F., y Babbini, I. (2020). Fortalecimiento de redes de autocuidado mediante Investigación Acción-Participativa en barrios populares argentinos durante la pandemia por COVID-19. El caso de Puente de Fierro, La Plata. Innovación y Desarrollo Tecnológico y Social, 2(2), 252305. https://doi.org/10.24215/26838559e025

Clichevsky, N. (2003). Pobreza y acceso al suelo urbano. Algunos interrogantes sobre políticas de regulación en América Latina. División de Desarrollo Urbano Sostenible. CEPAL. 
Clichevsky, N. (2007). La tierra vacante "revisitada". Elementos explicativos y potencialidades de utilización. En Cuaderno Urbano, 6(6), 195-2019 https://doi.org/10.30972/crn.661023

Cortizo, D. (2020). Tierras vacantes: Estado y mercado en los procesos de crecimiento urbano. Estrategias para su gestión en el Partido de La Plata. [Tesis de doctorado no publicada]. Facultad de Humanidades y Ciencias de la Educación, Universidad Nacional de La Plata.

Decreto de Ordenanza 10459. Programa Chau Baldío. Concejo Deliberante, Sesión Extraordinaria $\mathrm{N}^{\circ} 1$. La Plata, 20 de noviembre de 2008. https://www.concejodeliberante. laplata.gob.ar/digesto/or10500/or10459.asp

Delgado, M. (1999). El animal público. Editorial Anagrama.

Fernández Marín, S. (2016). La ciudad frente a la incertidumbre. Planificación urbana y organización en un escenario de probabilidad. Le Havre, 1935-1970. Territorios en Formación, 10, 21.https://doi.org/10.20868/tf.2016.10.3254

Frediani, J. (2016) La política de manejo de la tierra vacante en el Gran La Plata, Buenos Aires. Cuaderno Urbano, 20(20), 27. https://doi.org/10.30972/crn.2020941

Garay D. y Fernández, L. (2013). Biodiversidad urbana. Apuntes para un sistema de áreas verdes en la Región Metropolitana de Buenos Aires. Los Polvorines. Universidad Nacional de General Sarmiento.

Gehl, J. (2006). La humanización del espacio urbano: la vida social entre los edificios. Reverte.

Gifreu Font, J. (2016). La activación de la temporalidad urbana como paradigma de una gestión adaptativa y participativa. En M. Fernández y J. Gifreu (Dir.), El uso temporal de los vacíos urbanos (pp. 132-142). Diputación de Barcelona.

Han, B. (2020). Un filósofo surcoreano es tendencia por sus 9 definiciones sobre el COVID-19. https://www.mdzol.com/ mundo/2020/5/17/un-filosofo-surcoreano-es-tendenciapor-sus-definiciones-sobre-el-covid-19-79774.html
Hernández, J. (27 octubre de 2011). Producción de hábitat en América Latina. Barrios populares: retos y oportunidades [Sesión de conferencia]. Coloquio INJAVIU 2011. La dignidad humana en la ciudad latinoamericana: reflexiones para un nuevo paradigma de intervención en el territorio. Pontificia Universidad Javeriana, Bogotá, Colombia.

Instituto Nacional de Estadística y Censos de la República Argentina, INDEC (2010) Proyecciones de población. Autoedición.

Jofré, V. (13 de mayo de 2020). Villas miseria: el nuevo foco del Covid-19 en Buenos Aires. Diario la Tercera. https://www.latercera.com/mundo/noticia/villasmiseria-el-nuevo-foco-del-covid-19-en-buenosaires/4HBQCJ57WVGK3PIHCKI65J7A2A/

Ley Nacional $N^{\circ}$ 24.146. Transferencia de bienes del poder ejecutivo nacional a favor de las provincias, municipios. Decreto Nacional 776/1993. Buenos Aires, 21 de abril de 1993. Boletín Oficial, 26 de abril de 1993. https:// www.economia.gob.ar/digesto/leyes/ley24146.htm

Mourier, P. (1998). Le paysage comme espace public. École nationale supérieure du paysage, paysage (volumen 1 ). Editeur scientifique.

Myrick, P. (2020). The Recovery will Happen in Public Space. https://www.pps.org/article/the-recovery-will-happenin-public-space

Organización de las Naciones Unidas, ONU Hábitat III (2015). Public Space. Issue Papers 11. http://habitat3.org/wpcontent/uploads/Issue-Paper-11_Public_Space-SP.pdf

Organización de las Naciones Unidas, ONU Hábitat (2020). Espacio público y COVID-19. https://unhabitat.org/sites/ default/files/2020/06/spanishfinal_public_space_ key_messages_covid19.pdf

Parejo Alfonso, L. (2016). Urbanismo temporal, derecho a la ciudad y marco estatal de las políticas urbanas. En M. Fernández y J. Gifreu (Dir.), El uso temporal de los vacíos urbanos (pp. 100-106). Diputación de Barcelona. 
Pérez Valecillos, T. y Castellano Caldera, C. (2013). Creación del espacio público en asentamientos informales: nuevos desafíos urbanos. Bitácora Urbano Territorial, 2, 95-41. https://core.ac.uk/download/pdf/77267499.pdf

Relevamiento Nacional de Barrios Populares, RENABAP (2018). Conjunto de datos. En TECHO Argentina. https:// www.argentina.gob.ar/barriospopulares
Rodríguez Tarducci, R. (2020). Informalidad urbana en el Partido de La Plata, análisis del proceso de ocupación y apropiación territorial 1989-actualidad [Tesis de doctorado no publicada]. Facultad de Humanidades y Ciencias de la Educación. Universidad Nacional de La Plata.

Takano G. y Tokeshi, J. (2007). Espacio público en la ciudad popular: reflexiones y experiencias desde el Sur. Serie Estudios Urbanos, 3. http://observatoriourbano.org. pe/espacio-publico-en-la-ciudad-popular-reflexionesy-experiencias-desde-el-sur/ 